\title{
Impact of Mulberry Varieties on Biological Attributes of Bombyx mori L. (Lepidoptera: Bombycidae)
}

\author{
S.R. Patel", H.V. Pandya and Abhishek Shukla \\ Department of Entomology, N. M. College of Agriculture, Navsari Agricultural University, \\ Navsari-396 450, Gujarat, India \\ *Corresponding author
}

A B S T R A C T

\begin{tabular}{|c|c|}
\hline $\begin{array}{l}\text { Ke y w or d s } \\
\text { Mulberry varieties, }\end{array}$ & $\begin{array}{l}\text { The four improved mulberry varieties i.e. } \mathrm{S}_{30}, \mathrm{~S}_{36}, \mathrm{~S}_{41} \text {, and } \mathrm{TR}_{10} \text { were } \\
\text { introduced in mulberry garden of Department of Entomology, N. M. }\end{array}$ \\
\hline Article Info & \\
\hline $\begin{array}{l}\text { Accepted: } \\
\text { 20 September } 2017 \\
\text { Available Online: } \\
10 \text { November } 2017\end{array}$ & $\begin{array}{l}\text { weight, body measurement and economic characters. The next best cultivar } \\
\text { for these characters was } \mathrm{TR}_{10} \text {. The larvae reared on } \mathrm{S}_{41} \text { cultivar showed } \\
\text { inferior results in respect of economic characters. }\end{array}$ \\
\hline
\end{tabular}

\section{Introduction}

Moriculture is extensively practiced in the states of Karnataka, West Bengal, Jammu and Kashmir, Tamil Nadu and Andhra Pradesh. Among them, Karnataka is leading state in the production of mulberry silk in the country. Rearing of mulberry silkworm is also practiced to the lesser extent in the states like Maharashtra, Gujarat, Madhya Pradesh, Bihar, Orissa, Punjab, Haryana, Tripura, Nagaland and Meghalaya. In Gujarat, Jari industry has drawn attention both by farmers as well as scientists. In Surat city alone, where Jari industries are working, needs 400 to 500 tons of raw silk every year. Considering the requirements of silk, State Government took interest in sericulture and introduced mulberry plantation in 1984. Over and above, the land of South Gujarat is most suitable for mulberry cultivation.
Thus, the requirements of silk for industries coupled with suitability of mulberry cultivation played significant role in development of sericulture in Gujarat. It is well developed in districts like Navsari, Surat, Valsad, Bharuch, Vadodara, Kheda, Ahmedabad and Mehsana (Vakil, 1990).Farmers of the state realized the scope of sericulture and started shifting to sericulture from traditional cultivation of crops like sugarcane, cotton, tobacco and others.

Mulberry silkworm is quite delicate and very sensitive to environmental conditions. Growth, development and survival of the Bombyxmori is influenced by the environment, leaf quality and rearing techniques (Krishnaswami, 1994). Silkworm 
rearing remains continuous in tropical areas and most seasonal in subtropical and temperate zone. However, the rearing conditions prevailing at rearer's level are not always conducive in tropics. Mulberry silkworm (Bombyxmori L.) sustains its nutrition from its food plants of different species of mulberry (Morus sp.).

The nutritional levels of different varieties of mulberry influence the larval growth of silkworm, which ultimately influence the economic traits - such as yield, cocoon, shell weight and silk percentage of silkworm. There are 560 different mulberry varieties available all over the world, only a few of them are being exploited commercially at the field level for silkworm rearing. In south India, predominant varieties of mulberry are Mysore local and K-2 or M-5. Recently, the high yielding improved varieties such as $\mathrm{S}-30$, S-36, S-41 and S-54 are available for field exploitation.

\section{Materials and Methods}

Studies were conducted at Sericulture Laboratory, Department of Entomology, N.M. College of Agriculture, Navsari Agricultural University, Navsari, Gujarat. The experiment consisted of single silkworm race $\mathrm{PM} \times \mathrm{CSR}$ 2 which was tested on four mulberry varieties viz., S-30, S-36, S-41 and TR-10.

The Disease free layings of PM $\times$ CSR 2 was procured from Central Silk Board, Bangalore. Eggs were kept for hatching in the laboratory at room temperature and care was taken to protect the eggs from ants. After hatching of the eggs, tender mulberry leaves as per the treatments was chopped into small pieces and sprinkled over the newly hatched young larvae, which crawled on the leaves and started feeding from cut edges. Subsequently after 30 minutes the newly hatched larvae together with mulberry food was transferred into the rearing trays with the help of brush. The bed was made in a uniform size as per space required to the larvae. The mass rearing was followed during first instars. After second moult, hundred larvae were taken in each treatment and repeated five times. Larvae were fed with weighted quantity of leaves in each treatment till the maturity of the larvae. Weighted quantity of leaves was kept as control separately for determining the weight loss due to moisture loss in the leaves and this difference was subtracted from that of weight of fed leaves and thus, real quantity of leaves fed was worked out. The improved technology of silkworm rearing was followed during present investigation.

The food, spacing and cleaning was done as per the stages of the larvae and requirements. The equal quantity of food was given every time, which was thoroughly chopped as per the requirement before feeding. Four feedings of chopped mulberry leaves was given in a day.

The timing of feedings was fixed at 6.00 a.m., 11.00 a.m., 16.00 p.m. and 21.00 p.m. in a day. The size of the chopped leaves was regulated according to conditions and size of the larvae. During moulting the larvae were not provided any food and not disturbed. The quantity of food was increased as per the growth of the silkworm.

After the full development, the matured larvae was identified as they ceased to eat and looked translucent with creamy color. Such type of larvae was handpicked and kept on the mountage for spinning the cocoon as per the treatments and replications. Larvae were allowed to spin the cocoon for 48-72 hours.

The yield of cocoons and their economic characters was recorded as per the standard methodology of silkworm rearing. Reeling of cocoons was done in the laboratory. 


\section{Results and Discussion}

Effect of feeding different mulberry varieties on growth and development of mulberry silkworm Bombyx mori L.

\section{Larval growth parameters of mulberry silkworm $B$. mori}

\section{Effect on width of head capsule of larvae}

The freshly hatched larvae of PM $\times$ CSR 2 were reared on different mulberry cultivars. The measurement of the width of head capsule of successive instars was taken with the help of ocular micrometer. The observations noted have been presented in Table 1.

The data in Table 1 showed that the mean width of first, second, third, fourth and fifth instar larvae were $0.460,0.969,1.540,2.129$ and $2.755 \mathrm{~mm}$, respectively (Fig. 1).

The larvae reared on S-30 variety significantly had higher head capsule width in all the five instars which was $0.467,0.988$, $1.819,2.360$ and $3.001 \mathrm{~mm}$, respectively and it was followed by those reared on TR-10 and S-36. However, the larvae grown on leaves of cultivar S-41 showed least growth of head capsule in first to fifth instar which was $0.461,0.946,1.305,1.927$ and $2.511 \mathrm{~mm}$, respectively.

\section{Effect on larval weight of mulberry silkworm B. mori}

Weight of ten larvae of PM $\times$ CSR2 was recorded after each moult. The average weight of ten newly hatched larvae recorded was 0.0041 g. Data on the weight of subsequent larval instars are presented in Table 2. The data in Table 2 indicated that the mean larval weight of second, third, fourth and fifth instar larvae was 0.078, 0.457,
$1.457,28.68 \mathrm{~g}$, respectively. The larvae reared on mulberry variety S-30 obtained significantly higher larval weight $(30.499 \mathrm{~g})$ which was followed by TR-10 (28.899 g), S$36(28.200 \mathrm{~g})$ cultivars of mulberry. The minimum weight recorded in larvae reared on S-41 mulberry cultivar (27.100 g) (Fig. 2).

Considering the fifth instar larvae as basis for weight gain as influenced by different cultivars, S-30 mulberry cultivar was most promising. The next promising cultivars in the descending order were TR-10, S-36 and S-41.

Effect of feeding different cultivars of mulberry on average length $(\mathrm{mm})$ and width $(\mathrm{mm})$ of fifth instar larvae of mulberry silkworm B. mori

The average length and width of the fifth instar larvae were measured in $\mathrm{mm}$ with scale. The data on length and width of the fifth instar larvae presented in Table 3.

The data in Table 3 indicated that the mean larval length of fifth instar larvae reared on different cultivars S-30, S-36, TR-10 and S41 was $37.91,37.28,37.53$, and $37.12(\mathrm{~mm})$, respectively. The length of larvae reared on S30 cultivar $(37.91 \mathrm{~mm})$ was significantly higher than all other cultivar tested. This was followed by TR-10 $(37.53 \mathrm{~mm})$ and S-36 $(37.28 \mathrm{~mm})$. The minimum length recorded in larvae reared on S-41 cultivar $(37.12 \mathrm{~mm})$ (Fig. 3).

The data in Table 3 indicated that the mean larval width of fifth instar larvae reared on different cultivars S-30, S-36, TR-10 and S41 was $4.70,4.45,4.56$ and $4.39 \mathrm{~mm}$, respectively. The width of larvae reared on S30 cultivar $(4.70 \mathrm{~mm})$ was significantly higher than all other cultivar tested. This was followed by TR-10 $(4.56 \mathrm{~mm})$ and S-36 (4.45 $\mathrm{mm})$. The minimum width recorded in larvae reared on S-41 cultivar $(4.39 \mathrm{~mm})$. 
Considering the length and width of fifth instar larvae as influenced by different cultivars S-30 mulberry cultivar was most promising. The next promising cultivars in the descending order were TR-10, S-36 and S-41.

Effect of feeding different mulberry cultivars on duration of larval instars of $B$. mori

Data on duration of different larval instars are presented in Table 4. It is observed from Table 4 that the duration of the larvae of PM $\times$ CSR2 reared on S-30, S-36, TR-10 and S41 cultivars showed slight variation recording total larval duration of 22.64, 22.04, 22.77 and 22.82 (days), respectively (Fig. 4).

The data in Table 4 clearly indicated that the average larval duration of first to fifth instar larvae of PM $\times$ CSR2 reared on different cultivars was $3.25,3.23,3.46,4.72$ and 7.91 (days). The total larval duration of the larvae reared on TR-10 was minimum (22.04 days) followed by S-30 (22.64 days), S-36 (22.77 days) and S-41 (22.82 days).
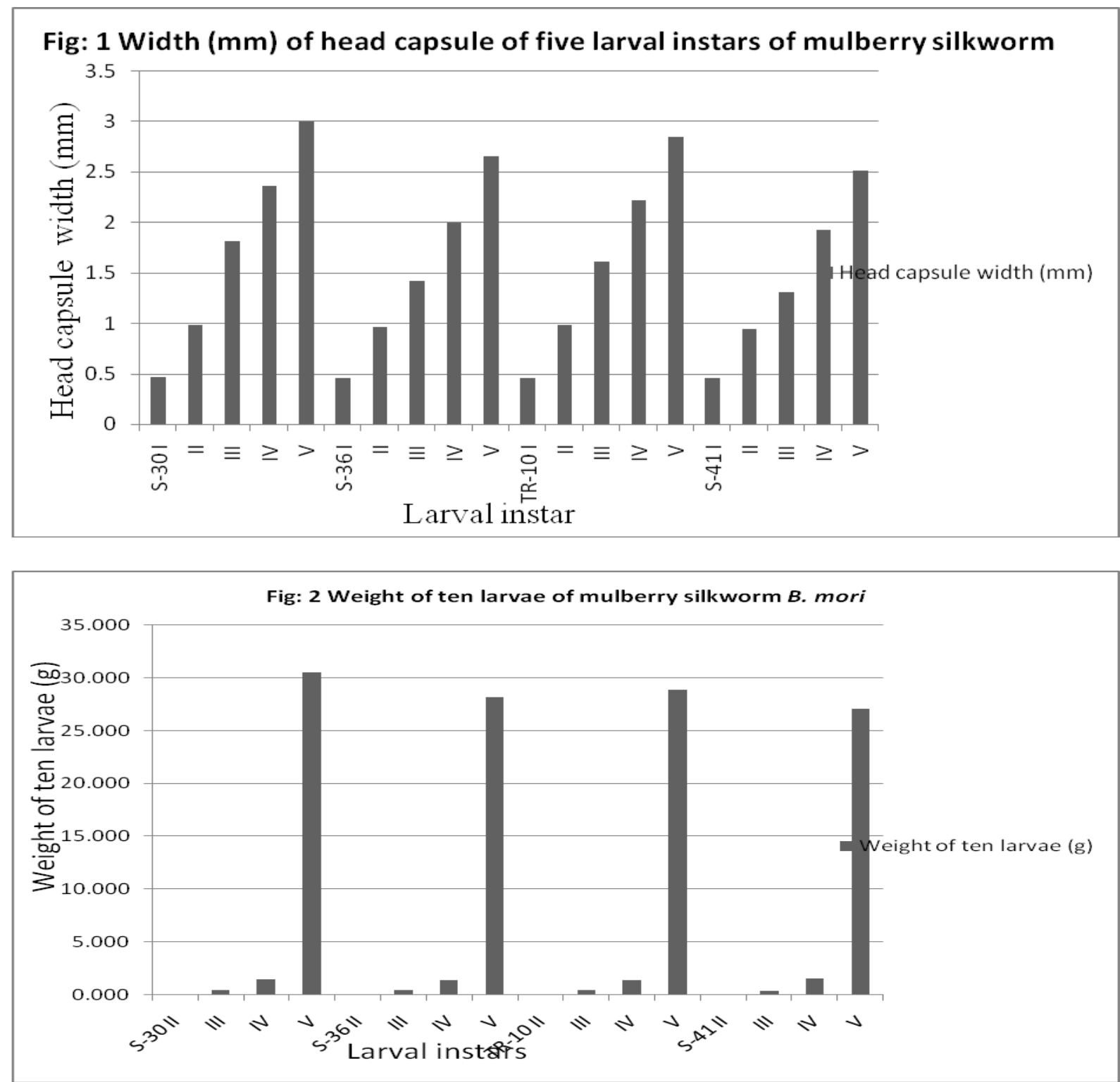


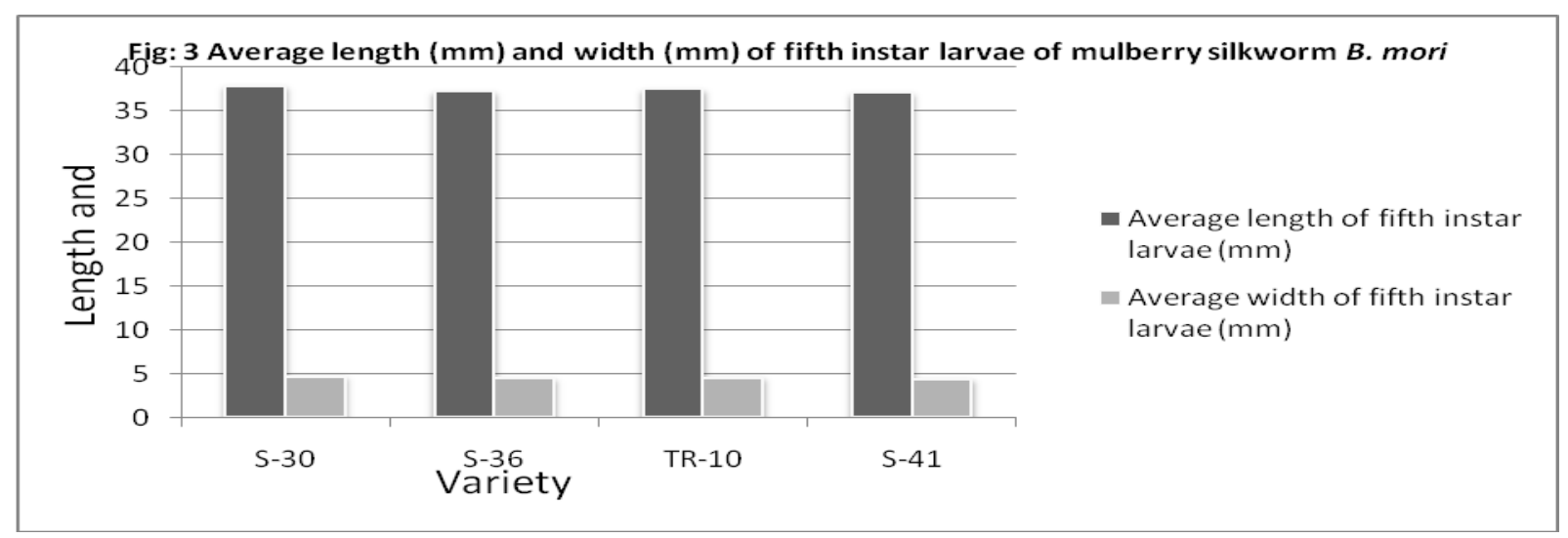

Table.1 Width (mm) of head capsule of five larval instars of mulberry silkworm B. mori reared during 2011-12

\begin{tabular}{|c|c|c|c|c|c|c|}
\hline \multirow{2}{*}{$\begin{array}{l}\text { Sr. } \\
\text { No. }\end{array}$} & \multirow{2}{*}{ Variety } & \multicolumn{5}{|c|}{ Larval instars } \\
\hline & & I & II & III & IV & $\mathrm{V}$ \\
\hline 1 & S-30 & 0.467 & 0.988 & 1.819 & 2.360 & 3.001 \\
\hline 2 & S-36 & 0.454 & 0.960 & 1.421 & 2.003 & 2.655 \\
\hline 3 & TR-10 & 0.459 & 0.980 & 1.615 & 2.225 & 2.851 \\
\hline \multirow[t]{4}{*}{4} & S-41 & 0.461 & 0.946 & 1.305 & 1.927 & 2.511 \\
\hline & Mean & 0.460 & 0.969 & 1.540 & 2.129 & 2.755 \\
\hline & SEm \pm & \multicolumn{5}{|c|}{0.020} \\
\hline & $\mathrm{CD}(0.05)$ & & & $0 .($ & & \\
\hline
\end{tabular}

Table.2 Weight of ten larvae of mulberry silkworm B. mori reared during 2011-12

\begin{tabular}{|c|c|c|c|c|c|}
\hline \multirow[t]{2}{*}{ Sr. No. } & \multirow[t]{2}{*}{ Variety } & \multicolumn{4}{|c|}{ Larval instars } \\
\hline & & II & III & IV & $\mathrm{V}$ \\
\hline 1 & S-30 & 0.082 & 0.469 & 1.512 & 30.499 \\
\hline 2 & S-36 & 0.076 & 0.488 & 1.376 & 28.200 \\
\hline 3 & TR-10 & 0.081 & 0.450 & 1.407 & 28.899 \\
\hline 4 & S-41 & 0.071 & 0.422 & 1.532 & 27.100 \\
\hline & Mean & 0.078 & 0.457 & 1.457 & 28.68 \\
\hline & SEm \pm & \multirow{2}{*}{\multicolumn{4}{|c|}{$\begin{array}{l}0.113 \\
0.321\end{array}$}} \\
\hline & $\mathrm{CD}(0.05)$ & & & & \\
\hline
\end{tabular}

Table.3 Average length $(\mathrm{mm})$ and width $(\mathrm{mm})$ of fifth instar larvae of mulberry silkworm B. mori reared during 2011-12

\begin{tabular}{|l|l|c|c|}
\hline Sr. No. & \multirow{2}{*}{ Variety } & \multicolumn{2}{|c|}{ Fifth instar larvae } \\
\cline { 3 - 4 } & & Length $(\mathrm{mm})$ & Width $(\mathrm{mm})$ \\
\hline 1 & S-30 & 37.91 & 4.70 \\
\hline 2 & S-36 & 37.28 & 4.45 \\
\hline 3 & TR-10 & 37.53 & 4.56 \\
\hline 4 & S-41 & 37.12 & 4.39 \\
\hline & SEm \pm & 0.006 & 0.008 \\
\hline & CD $(0.05)$ & 0.019 & 0.024 \\
\hline
\end{tabular}


Table.4 Average larval duration (days) of PM $\times$ CSR2 strain of $B$. mori fed with different cultivars during 2011-12

\begin{tabular}{|l|l|l|l|l|l|l|l|}
\hline \multirow{2}{*}{ Sr. No. } & \multirow{2}{*}{ Variety } & \multicolumn{6}{l|}{ Duration (days) of larval instars } \\
\cline { 3 - 8 } & & I & II & III & IV & V & Total \\
\hline 1 & S-30 & 3.28 & 3.36 & 3.47 & 4.70 & 7.83 & 22.64 \\
\hline 2 & S-36 & 3.27 & 3.30 & 3.51 & 4.73 & 7.96 & 22.77 \\
\hline 3 & TR-10 & 3.17 & 3.12 & 3.39 & 4.62 & 7.74 & 22.04 \\
\hline 4 & S-41 & 3.29 & 3.12 & 3.48 & 4.82 & 8.11 & 22.82 \\
\hline & Mean & 3.25 & 3.23 & 3.46 & 4.72 & 7.91 & 22.57 \\
\hline & SEm \pm & 0.015 & 0.044 & \multicolumn{4}{|l}{} \\
\hline & CD $(0.05)$ & 0.07 & & \\
\hline
\end{tabular}

Table.5 Duration of larval moult (hrs.) of B. mori fed with different cultivars during 2011-12

\begin{tabular}{|l|l|l|l|l|l|l|l|}
\hline \multirow{2}{*}{ Sr. No. } & \multirow{2}{*}{ Variety } & \multicolumn{4}{l|}{ Number of moult } & Total & \multirow{2}{*}{ Mean } \\
\cline { 3 - 6 } & & I & II & III & IV & & \\
\hline 1 & S-30 & 25.42 & 28.42 & 26.46 & 29.41 & 109.71 & 27.43 \\
\hline 2 & S-36 & 27.40 & 28.14 & 28.38 & 29.43 & 113.35 & 28.34 \\
\hline 3 & TR-10 & 26.32 & 29.45 & 27.43 & 30.25 & 113.45 & 28.36 \\
\hline 4 & S-41 & 28.44 & 30.14 & 29.47 & 31.18 & 119.23 & 29.81 \\
\hline & Mean & 26.90 & 29.04 & 27.94 & 30.07 & 113.94 & 28.48 \\
\hline & SEm \pm & 0.040 & \multicolumn{7}{|l}{} \\
\hline & CD $(0.05)$ & 0.114 & & & \\
\hline
\end{tabular}

Table.6 Relative order of different parameters for growth and development of B. mori on four mulberry cultivars

\begin{tabular}{|l|c|c|c|c|c|}
\hline \multirow{2}{*}{$\begin{array}{l}\text { Sr. } \\
\text { No. }\end{array}$} & Characters & \multicolumn{4}{|c|}{ Rank of variety } \\
\cline { 3 - 5 } & & 1 & 2 & 3 & 4 \\
\hline 1 & Head capsule width & S-30 & TR-10 & S-36 & S-41 \\
\hline 2 & Larval weight & S-30 & TR-10 & S-36 & S-41 \\
\hline 3 & Body measurement & S-30 & TR-10 & S-36 & S-41 \\
\hline 4 & Larval duration & S-30 & TR-10 & S-36 & S-41 \\
\hline 5 & Moulting period & TR-10 & S-30 & S-36 & S-41 \\
\hline 6 & Cocoon parameters & S-30 & S-36 & TR-10 & S-41 \\
\hline
\end{tabular}

On the basis of overall influence of various mulberry cultivars on larval duration of $\mathrm{PM} \times$ CSR2 strain of B. mori, it is concluded that the TR-10 was observed to be most suitable for rearing. Larvae reared on it showed lesser duration. The next promising cultivar was $\mathrm{S}$ 30. However, the difference in the larval duration recorded in case of larvae reared on different cultivars was only of few hours to only one day. Therefore, all the mulberry cultivars tested could be considered suitable for rearing of the $\mathrm{PM} \times \mathrm{CSR} 2$ strain of $B$. mori.

Effect of feeding of different cultivars of mulberry on duration of larval moulting of B. mori

The observations on effect of feeding on the moulting period of the larvae of $B$. mori were 
presented in Table 5. It is noticed from Table 5 that the mean moulting period of first, second, third and fourth moult was 26.90, 29.04, 27.94 and 30.07 hours, respectively.

The maximum duration of moulting was observed in the larvae reared on S-41 (29.81 hrs.) followed by TR-10 (28.36 hrs.) and S-36 (28.34 hrs.). The minimum moulting period recorded in the larvae reared on S-30 cultivar (27.43 hrs.).

On the basis of total moulting period, the larvae reared on S-30 cultivar showed the shortest period (109.71 hrs.) followed by those fed with S-36 (113.35 hrs.) and TR-10 (113.45 hrs.) cultivars. The longest moulting period was observed in the larvae fed with S41 cultivar (119.23 hrs.).

Effect of feeding different mulberry varieties on economic cocoon parameters of mulberry silkworm $B$. mori

The data in respect to different economic cocoon parameters like single cocoon weight, single shell weight, SR percentage, Effective rate of rearing by number and weight, filament length, Denier, Renditta and Raw silk recovery percentage are recorded after cocoon formation. Data on all these parameters are tabulated in Table 6.

The data in Table 6 also indicated that the larvae fed with S-30 variety recorded significantly higher single cocoon weight $(1.680 \mathrm{~g})$, single shell weight $(0.236 \mathrm{~g})$, SR percentage $(14.84 \%)$, Effective rate of rearing by number (7220) and length of filament $(615.20 \mathrm{~m})$ than all other varieties tested. It was also recorded that larvae fed with S-41 variety showed higher Renditta (9.33) and Raw silk recovery percentage $(64.99 \%)$. It is also observed that larvae fed with S-41 variety showed lowest single cocoon weight (1.509 g), SR percentage
(11.12\%), Effective rate of rearing by weight $(9.01 \mathrm{~kg})$ and length of filament $(557.20 \mathrm{~m})$.

The data presented in Table 6 indicated that the economic cocoon parameters like single cocoon weight, single shell weight, SR percentage, effective rate of rearing by number and weight, filament length, denier, renditta and raw silk recovery percentage of $\mathrm{PM} \times \mathrm{CSR} 2$ strain of $B$. mori showed the best results when reared on the leaves of mulberry cultivar S-30 followed by those reared on S36 and TR-10. However, the larvae reared on leaves of cultivar S-41 showed least cocoon parameters.

\section{Overall suitability of mulberry cultivars}

During present investigation an attempt was made to ascertain overall suitability of mulberry varieties for rearing B. mori. All important economic characters were considered while testing the suitability and scored by giving four points for the first position and reducing one point for subsequent position.

\section{Rating for economic character, growth and} development

Number of points to rank- $1=4,2=3,3=2$ and $4=1$.

The total score for each variety was considered in arranging them in the order of suitability. All varieties were arranged in ascending order for characters like larval duration and moulting period while characters like head capsule width, larval weight, body measurement like length and width of larvae and cocoon parameters, were arranged in descending order.

Thus, overall suitability of mulberry varieties as observed during present investigation was in the following descending order with 
respective total points obtained S-30 (22), TR-10 (18), S-36 (13) and S-41 (6) points.

The results obtained during present study are more or less in confirmatory with those reported in past (Anonymous, 1976) that was effect of feeding silkworms with five selected newly evolved strains of mulberry on larval health and cocoon characters.

In Annual Report 1975-76 of Central Sericultural Research and Training Institute, Mysore. It was reported that S-30 gave the best results maximum weight of $33.88 \mathrm{~g}$ for ten larvae followed by S-36 and S-29. Survival rate was more in S-30 variety. Cocoon weight was found to be highest in case of S-30 followed by S-36.

The present results are also in confirmatory with those recorded by Nataraju et al., (1980). They reported highest single cocoon weight in mulberry variety S-30 and S-54.

\section{Acknowledgments}

The authors are highly thankful to Professor and Head, Department of Entomology, N.M. College of Agriculture and to the Principal, N. M. College of Agriculture as well as Director of Research and Dean P.G. Studies, Navsari
Agricultural University, Navsari, Gujarat, India for providing necessary facilities for conducting the present research work.

\section{References}

Anonymous 1976. Effect of feeding silkworms with five selected newly evolved strains of mulberry on larval health and cocoon characters. Annual Report 1975-76, Central Sericultural Research and Training Institute, Mysore, pp. 98-99.

Krishnaswami, S. 1994. A practical guide to mulberry silk cocoon production in tropics. Sriramula Sericulture Consultants, Bangalore, India, pp. 4950.

Nataraju, B., Murthuza, Baig, Rajagopalan Raju, Krishnaswami, S. and Serson, M. V. 1980. Feeding trials with different varieties of mulberry in relation to cocoon crop performance and incidence of loss due to diseases. Proceedings of seri. Symposia and Seminar held at Tamil Nadu, Coimbatore, 43-50.

Vakil, V. 1990.Economic prosperity through sericulture in villages of Surat district. A special report in Abhiyan, Dec., 1990.pp. 11-13.

\section{How to cite this article:}

Patel, S.R., H.V. Pandya and Abhishek Shukla. 2017. Impact of Mulberry Varieties on Biological Attributes of Bombyx mori L. (Lepidoptera: Bombycidae). Int.J.Curr.Microbiol.App.Sci. 6(11): 2503-2510. doi: https://doi.org/10.20546/ijcmas.2017.611.294 